\title{
Maternal blood manganese level and birth weight: a MOCEH birth cohort study
}

\author{
Jin-Hee Eum ${ }^{1,2}$, Hae-Kwan Cheong ${ }^{1,2^{*}}$, Eun-Hee Ha ${ }^{3}$, Mina Ha ${ }^{4}$, Yangho Kim5 ${ }^{5}$ Yun-Chul Hong ${ }^{6}$, Hyesook Park ${ }^{3}$ \\ and Namsoo Chang $^{7}$
}

\begin{abstract}
Background: Manganese (Mn) is an essential trace element for humans and animals, but excess intake of Mn can lead to adverse developmental outcome. Few studies have investigated the effects of deficiency or excess of Mn on the human foetus. In this study, we assessed the quantitative relationship between maternal blood $\mathrm{Mn}$ and birth weight of a newborn.

Methods: We performed analysis on 331 full-term, live birth singleton mother-infant pairs enrolled from July 2007 to December 2009 in the Mother and Children's Environmental Health (MOCEH) study in Korea. A questionnaire on general characteristics, a review of medical records, and maternal whole blood $\mathrm{Mn}$ analysis were performed at full-term pregnancy. We evaluated the relationship between maternal blood level of $\mathrm{Mn}$ and the birth outcome using logistic regression and generalised additive model.

Results: The mean Mn concentration in whole maternal blood was $22.5 \mu \mathrm{g} / \mathrm{L}$. We found a curvilinear relationship between maternal blood $\mathrm{Mn}$ and birth weight after adjusting for potential confounders. Birth weight peaked at the maternal blood $\mathrm{Mn}$ level of 30 and $35 \mu \mathrm{g} / \mathrm{L}$. An increased probability of birth weight below $3000 \mathrm{~g}$ was observed at both below $16.9 \mu \mathrm{g} / \mathrm{L}$ (odds ratio $=2.77,95 \% \mathrm{Cl}$ : 0.89-8.65) and above $26.9 \mu \mathrm{g} / \mathrm{L}$ of maternal blood $\mathrm{Mn}$ level (odds ratio $=2.66,95 \% \mathrm{Cl}: 0.84-8.08)$.
\end{abstract}

Conclusions: Our study found that both extreme level of maternal Mn level was associated with lower birth weight outcome in a nonlinear fashion.

Keywords: In utero environment, Birth outcome, Birth cohort, Foetal development, Dose-response relationship, Manganese

\section{Introduction}

Manganese $(\mathrm{Mn})$ is one of the essential nutrients for humans and animals [1]. It is required for energy metabolism, development of the skeletal system, activation of certain enzymes, function of reproductive hormones, and antioxidant functions that protect cells [1,2]. Mn deficiency may result in poor bone formation, birth defects, and increased susceptibility to seizures [3-5]. Such a health outcome is, however, rarely reported in humans because the element is widely present in common foods [6].

\footnotetext{
* Correspondence: hkcheong@skku.edu

'Department of Social and Preventive Medicine, Sungkyunkwan University School of Medicine, 2066 Seobu-ro, Jangan-gu, Suwon, Gyeonggi-do 440-746, Republic of Korea

${ }^{2}$ Department of Social and Preventive Medicine, Samsung Biomedical Research Institute, Sungkyunkwan University School of Medicine, 81 Irwon-ro, Gangnam-gu, Seoul 135-990, Republic of Korea

Full list of author information is available at the end of the article
}

Pregnant women and infants typically show an increase in blood Mn level, which becomes more prominent in the later phase of pregnancy [7]. High Mn demands of the developing foetus during pregnancy lead to increased blood Mn level. Foetuses and neonates could be at higher risk for the toxic effects of high Mn exposure because they do not have fully developed homeostatic mechanisms for Mn [8]. Generally, adults maintain stable blood Mn concentrations by $\mathrm{Mn}$ homeostasis, which is achieved by regulation of absorption and excretion [1]. Studies demonstrate increased gastrointestinal absorption of Mn [9] and decreased ability to eliminate Mn [10,11].

Mn-related maternal and developmental toxicities have been observed in studies of experimental animals, including reduced foetal body weight and high Mn level $[12,13]$. Few epidemiologic studies reported the relationship between 
maternal blood Mn level and birth weight of pregnancy outcome in human $[14,15]$. In a study in Teheran, Iran, intrauterine growth retardation was linearly associated with lower maternal blood Mn level, but with higher cord blood Mn level [14]. In another study, birth weight was biphasically associated with maternal blood $\mathrm{Mn}$ concentration in an inverted U-shaped dose-response relationship [15]. This study was conducted in a population living near a lead and zinc mining site in northeastern Oklahoma, U.S.A., with a potential environmental metal exposure. There are few reports on the birth outcome of Mn level during pregnancy in the general population [16]. Also, the effect of the very low level of Mn was less explored. Little is known about the effects of deficiency or excess of $\mathrm{Mn}$ on infant growth or birth outcome in humans [16]. Uncertainty still remains about the degree which Mn level will be adequate for pregnant woman. The objective of this study was to assess the association between maternal blood $\mathrm{Mn}$ concentrations during pregnancy and birth weight in the general population without a prominent source of $\mathrm{Mn}$ exposure.

\section{Methods}

\section{Study subjects}

This analysis was conducted on a community-based birth cohort study, the Mothers and Children's Environmental Health (MOCEH) study. MOCEH is designed to investigate the effects of pregnant women's environmental exposure on foetal and postnatal growth and development in three centres; Seoul, Cheonan, and Ulsan, Republic of Korea [17]. Among 953 participants recruited until 2009, research committee of MOCEH approved blood sampling for $\mathrm{Mn}$ on 352 pregnant women consecutively recruited between July 2007 and December 2009 from three centres. Study subjects agreed to undergo maternal blood $\mathrm{Mn}$ analysis and had available birth records. For the analysis, we excluded stillborn baby $(\mathrm{n}=1)$, pregnancy-related diabetes $(N=3)$, severe foetal stress $(N=4)$, twins $(n=4)$, and preterm $(<37$ weeks, $\mathrm{n}=8)$ and over-term $(\geq 42$ weeks, $\mathrm{n}=1$ ) infants, leaving 331 mother-infant pairs as study subjects.

This study protocol was approved by the institutional review boards of Ewha Womans University, Dankook University Hospital, and Ulsan University Hospital. Informed consent was obtained from all the study participants at the time of recruitment.

\section{Methods}

Data were collected by a questionnaire and from each woman's medical records before 20 weeks of gestation by a trained nurse at the outpatient clinic and at the time of visit for delivery. The questionnaire consisted of socio-demographic information such as mailing address, age, height, weight, occupation, education, and income; pre-pregnancy alcohol consumption; smoking history; complications of the current pregnancy; and the subject's biological, medical, and obstetric history. At delivery, trained nurses measured birth weight using a digital scale.

Medical records were reviewed to collect information on maternal pre-pregnancy weight, maternal height, gestational age, parity information, delivery mode, infant sex and birth weight, presence of preterm birth or low birth weight, delivery date, maternal term weight and presence of intrapartum complications including premature rupture of membranes, cephalopelvic disproportion, dystocia, breech presentation or other abnormal position, placenta abruption, placenta previa, meconium aspiration syndrome, foetal asphyxia, obstetrical haemorrhage, precipitating labour, cord prolapse or eclampsia during labour, fever, and use of anaesthetics.

\section{Blood collection}

Maternal venous blood samples $(10 \mathrm{ml})$ were obtained at the visit for delivery and stored at $-70^{\circ} \mathrm{C}$ until it was transferred to the laboratory at the Neodin Medical Institute for analysis. Whole blood Mn level was measured by graphite furnace atomic absorption spectrophotometry (AAnalyst 600, PerkinElmer, Waltham, MA, USA). The laboratory analyses were conducted using standardised quality-control procedures from the German External Quality Assessment Scheme and Institute and Outpatient Clinic for Occupational, Social and Environmental Medicine of the University of Erlangen-Nuremberg as described by Kim et al. [17]. The relative standard deviation of the analysis was below $5 \%$. The limit of detection for $\mathrm{Mn}$ was $1.585 \mu \mathrm{g} / \mathrm{L}$ and all samples were above the limit of detection.

\section{Data analysis}

The distribution of maternal blood $\mathrm{Mn}$ was slightly skewed to the right (skewness $=1.3$ ), but the distribution was close to Gaussian except for outliers above the 99th percentile value. Therefore, we did not transform it to a log scale. Student's t-test or ANOVA was performed for unadjusted group differences in maternal blood $\mathrm{Mn}$ and birth weight. We assessed the association between maternal Mn level and birth weight by simple regression analysis and then by multiple regression analysis using a second degree polynomial function after adjusting for potential confounders (infant sex, gestational age, maternal education, maternal parity, maternal term weight, maternal income, and maternal age), which were determined from previous studies $[6,14,15,18,19]$.

Multiple logistic regression was used to assess the relationship between maternal blood $\mathrm{Mn}$ and the birth outcome after adjusting for the potential confounders. We categorised the birth weight variable as binary data: lower than $3000 \mathrm{~g}$ (which represented less than 
Table 1 Distribution of blood manganese concentration and birth weight by general characteristics of the study subjects

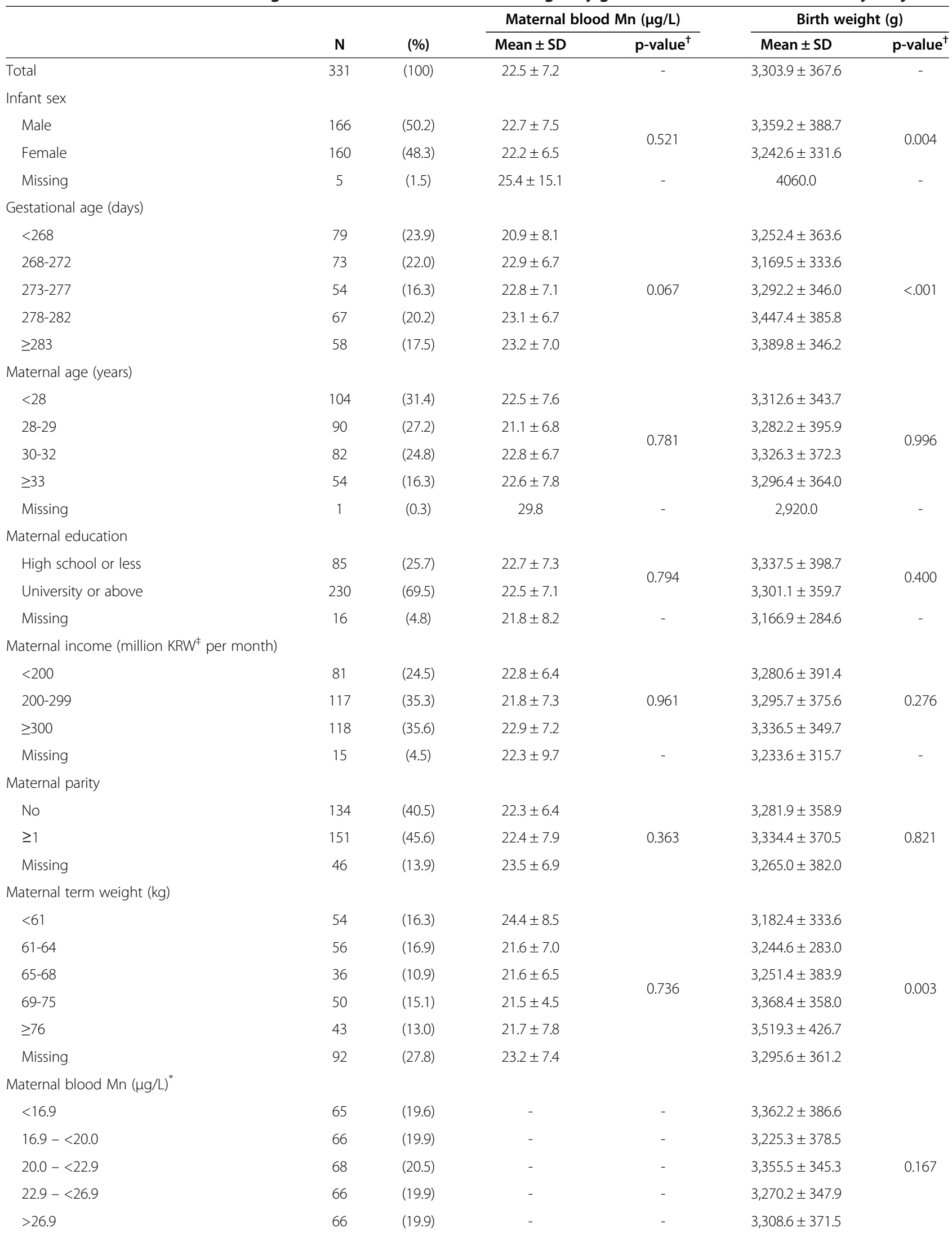


Table 1 Distribution of blood manganese concentration and birth weight by general characteristics of the study subjects (Continued)

\begin{tabular}{|c|c|c|c|c|c|c|}
\hline \\
\hline \multicolumn{7}{|c|}{$\begin{array}{l}\text { Birth weight (quintile, g) } \\
<3000\end{array}$} \\
\hline 3000-3199 & 65 & (20.0) & $21.5 \pm 6.1$ & & - & - \\
\hline 3200-3399 & 66 & (20.3) & $21.8 \pm 6.0$ & 0.608 & - & - \\
\hline $3400-3599$ & 64 & (19.7) & $22.8 \pm 7.1$ & & - & - \\
\hline$\geq 3600$ & 71 & (21.9) & $23.2 \pm 7.4$ & & - & - \\
\hline
\end{tabular}

${ }^{\dagger}$ Tested by ANOVA (tested for linear trend in case of ordinal variables) or t-test.

${ }^{\ddagger} 10^{6} \mathrm{KRW}=1050$ USD as of Jan 2008.

${ }^{*}$ The $8 \mu \mathrm{g} / \mathrm{L}$ unit categories of blood $\mathrm{Mn}$.

$(\mathrm{N}=331)$.

20 percentile among the study population) or equal or more than 3000 g. Non-linear relationships were examined by a generalised additive model (GAM) after controlling for potential confounders. Statistical analyses were performed using SAS 9.3 software (SAS Institute Inc., Cary, NC, USA) and $\mathrm{R}$ software ( $\mathrm{R}$ version 3.0.1). Statistical significance was determined using a $p$ value of $<0.05$.

\section{Results}

The arithmetic mean (SD) of blood Mn concentration in this study population was $22.5(7.2) \mu \mathrm{g} / \mathrm{L}$, ranging from 8.5 to $58.6 \mu \mathrm{g} / \mathrm{L}$, and the median was $21.5 \mu \mathrm{g} / \mathrm{L}$. Mean infant birth weight was 3303.9 (367.6) g, and mean maternal age was 30.3 (3.6) years. The gestational age and maternal term weight were significantly associated with birth weight, but only gestational age was associated with maternal blood $\mathrm{Mn}$ in borderline level of significance ( $\mathrm{p}=0.067)$ (Table 1).

When we evaluated the quadratic association of $\mathrm{Mn}$ on birth outcome using a multiple linear regression model, a borderline level of significance was found between blood $\mathrm{Mn}$ and birth weight $(\mathrm{p}=0.054)$ after controlling for possible confounders including infant sex, gestational age, maternal education, maternal parity, maternal term weight, maternal income, and maternal age (Table 2).

Table 3 shows the association between maternal blood $\mathrm{Mn}$ and infant birth weight. Multiple logistic regression analysis was performed to assess the relationship between maternal Mn level and binary categorised birth weight (below $3000 \mathrm{~g}$ or more than $3000 \mathrm{~g}$ ) after categorising the
Mn level into five levels. Both lowest $(<16.9 \mu \mathrm{g} / \mathrm{L})$ and highest $(\geq 26.9 \mu \mathrm{g} / \mathrm{L})$ categories of maternal blood $\mathrm{Mn}$ levels were associated with birth weight below $3000 \mathrm{~g}$ infants; the odds ratio of the former was 2.77 (95\% CI: $0.89-8.65)$ and the latter was 2.60 (95\% CI: $0.84-8.08)$, although it was significant at borderline level $(\mathrm{p}=0.079$ and $\mathrm{p}=0.098$, respectively).

We obtained consistent results with the generalised additive model, showing that low and high levels of $\mathrm{Mn}$ were associated with birth weight below $3000 \mathrm{~g}$. The birth weight gradually increased up to level of $30 \mu \mathrm{g} / \mathrm{L} \mathrm{Mn}$, then after a peak between 30 and $35 \mu \mathrm{g} / \mathrm{L}$, decreased at over $35 \mu \mathrm{g} / \mathrm{L}$ level (Figure 1).

\section{Discussion}

The results of our multicentre cohort study indicated that both low and high blood Mn level of pregnant women is associated with birth weight below $3000 \mathrm{~g}$ of infants. We further identified a curvilinear relationship between maternal blood $\mathrm{Mn}$ level and infant birth weight, in accordance with previous report [14].

It shows that a high level of blood $\mathrm{Mn}$ is associated with lower birth weight in full-term infants. A high maternal Mn level, over $36 \mu \mathrm{g} / \mathrm{L}$, was borderline significantly associated with birth weight below $3000 \mathrm{~g}$ although the relationship between high $\mathrm{Mn}$ level and lower birth weight in our study population was rather weak. The report of Zota et al. [15] found a consistent relationship between blood Mn and birth weight in the area of the Tar Creek Superfund site, an area contaminated with mining

Table 2 Regression analysis of birth weight and maternal blood Mn concentration

\begin{tabular}{|c|c|c|c|c|c|c|c|c|c|}
\hline & \multicolumn{3}{|c|}{ Model $1^{\neq}$} & \multicolumn{3}{|c|}{ Model $2^{\dagger}$} & \multicolumn{3}{|c|}{ Model $3^{\dagger}$} \\
\hline & Beta & SE & $p$-value & Beta & SE & $p$-value & Beta & SE & $p$-value \\
\hline Maternal Mn & 3.39 & 2.90 & 0.244 & 2.65 & 2.87 & 0.356 & 23.48 & 12.14 & 0.054 \\
\hline Maternal $\mathrm{Mn}^{2}$ & - & - & - & - & - & - & -0.38 & 0.22 & 0.079 \\
\hline Model $p$ value & \multicolumn{3}{|c|}{0.244} & \multicolumn{3}{|c|}{$<0.001$} & \multicolumn{3}{|c|}{$<0.001$} \\
\hline Adjusted $R^{2}$ & \multicolumn{3}{|c|}{0.001} & \multicolumn{3}{|c|}{0.163} & \multicolumn{3}{|c|}{0.169} \\
\hline
\end{tabular}

${ }^{\ddagger}$ Unadjusted model, ${ }^{\dagger}$ Adjusted for infant sex, gestational age, maternal education, maternal parity, maternal term weight, maternal income, and maternal age $(\mathrm{N}=325)$. 
Table 3 Logistic regression analysis of birth weight below $3000 \mathrm{~g}$ and maternal blood $\mathrm{Mn}$ concentration

\begin{tabular}{lcccc}
\hline $\begin{array}{l}\text { Maternal blood } \\
\text { manganese level } \\
(\boldsymbol{\mu} \mathbf{g} / \mathbf{L})\end{array}$ & $\begin{array}{c}\text { No. of } \\
\text { subjects }\end{array}$ & AOR $^{+}$ & $\begin{array}{c}\text { 95\% confidence } \\
\text { interval }\end{array}$ & $\boldsymbol{p}$-value \\
\hline$<16.9$ & 66 & 2.77 & $(0.89-8.65)$ & 0.079 \\
$16.9-<20.0$ & 65 & 1.41 & $(0.42-4.79)$ & 0.580 \\
$20.0-<22.9$ & 65 & 2.43 & $(0.79-7.52)$ & 0.123 \\
$22.9-<26.9$ & 65 & 1.00 & - & - \\
$>26.9$ & 65 & 2.60 & $(0.84-8.08)$ & 0.098 \\
\hline
\end{tabular}

${ }^{\dagger}$ Adjusted odds ratio, adjusted for infant sex, gestational age, maternal education, maternal parity, maternal term weight, maternal income, and maternal age.

waste. They reported an inverted U-shaped relationship with a concentration of $31 \mu \mathrm{g} / \mathrm{L}$ as the point of inflection between maternal blood $\mathrm{Mn}$ and birth weight. However, the mean concentration of maternal whole blood $\mathrm{Mn}$ was $2.4 \mu \mathrm{g} / \mathrm{dL}$, which is higher compared to the level of our study population, and this difference was especially evident at the 95th percentile $(4.1 \mu \mathrm{g} / \mathrm{dL}$ compared with $3.6 \mu \mathrm{g} / \mathrm{dL}$ in our study, data not shown), presumably because of potential environmental exposure related with the closed mine. Recent two China studies observed an inverted U-shaped relationship of maternal $\mathrm{Mn}$ and cord blood Mn with birth weight. In Shanghai study [20], they found that maternal $\mathrm{Mn}$ was associated with birth weight $(\mathrm{n}=175$, mean of maternal whole blood $\mathrm{Mn}=6.6 \mu \mathrm{g} / \mathrm{dL}$, mean of umbilical cord blood $\mathrm{Mn}=8.5 \mu \mathrm{g} / \mathrm{dL}$ ). In Dalian city study [21], northern China, significant relationship was observed between cord blood $\mathrm{Mn}$ and birth weight $(\mathrm{n}=125$, mean of maternal whole blood $\mathrm{Mn}=55.0 \mu \mathrm{g} / \mathrm{L}$, mean of umbilical cord blood $\mathrm{Mn}=78.8 \mu \mathrm{g} / \mathrm{L}$ ). The former study found that the birth weight increased $\mathrm{Mn}$ levels up to $4.18 \mu \mathrm{g} / \mathrm{dL}$, the peak point of the latter study was $90.0 \mu \mathrm{g} / \mathrm{L}$, and then decreased. The Mn concentrations of these studies were higher than other studies $[14,15,22]$.

Another study conducted in Southwest Quebec also tested the hypothesis of an inverted U-shaped relationship, but did not obtain a significant association between maternal blood Mn and birth outcome. This study had a small sample size $(\mathrm{n}=101)$ and the maternal Mn level $(16.3 \mu \mathrm{g} / \mathrm{L})$ was much lower than that in our study [22]. In Shanghai study [23], serum Mn from both cord blood and maternal blood were used as biomarkers, with the median maternal and cord serum level of $2.8 \mu \mathrm{g} / \mathrm{dL}$ and $4.0 \mu \mathrm{g} / \mathrm{dL}$, respectively. The authors examined the relationship between cord serum $\mathrm{Mn}$ and birth weight by multiple regression, and did not find a significant association between them, although they found a negative relationship and nonlinear relationship between cord serum $\mathrm{Mn}$ and birth length and Ponderal index, respectively [23]. Because blood Mn level in the cord blood is higher than that in maternal blood at the time of delivery $[20,21]$ and this study was conducted with serum, it cannot be directly comparable to our study.

Many studies reported the effects of Mn deficiency in animals, but human study is rare [3] to our knowledge. This may reflect inadequacy of data from developing countries or a lack of data on deficiency of Mn during pregnancy in developed countries. The most common

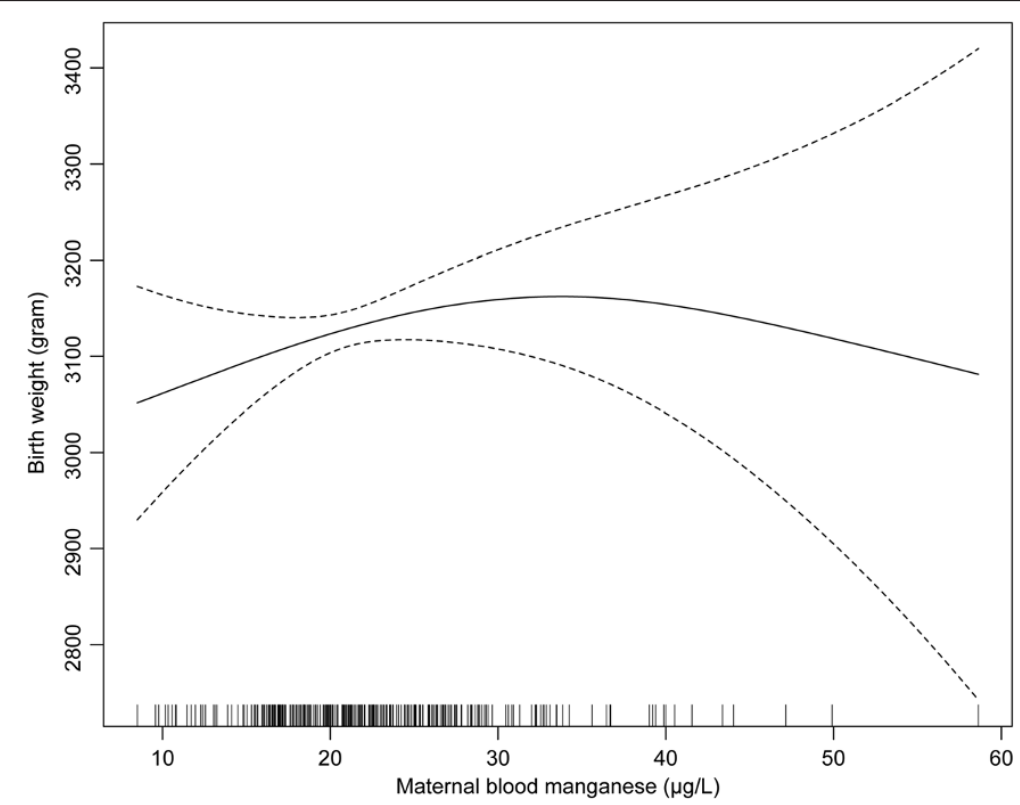

Figure 1 Nonlinear association between birth weight and maternal blood Mn level. ${ }^{\dagger}$ adjusted for infant sex, gestational age, maternal education, maternal parity, maternal term weight, maternal income, and maternal age. 
features of Mn deficiency in animals were skeletal malformation, and deprivation of $\mathrm{Mn}$ intake results in abnormal glucose tolerance and perturbation of lipid and carbohydrate metabolism [24-28].

This study has a relatively small number of observations, especially at high Mn concentration range, which obscures the relationship at very high levels of maternal blood $\mathrm{Mn}$. In addition, as we did not examine the association between umbilical cord blood Mn levels and birth weight, and maternal blood sampling during pregnancy was not measured. Thus, the temporal relationship between $\mathrm{Mn}$ level and birth outcome is unclear. We could not take the point that iron and Mn share uptake mechanisms into account, because the information on the maternal intake of nutritional supplement including iron and calcium, and iron-related health problems including anaemia were not available and prevalence of anaemia was very low. A study conducted in Sweden indicates that Mn level during pregnancy was not related to iron status [29].

Our results confirm the non-linear relationship reported in a previous human study [15] and the association between Mn exposure and lower birth weight in animal studies [30] even though our study was conducted on a female population without any specific environmental or occupational source of exposure.

\section{Conclusions}

Our study found that both extreme level of maternal Mn level was associated with lower birth weight outcome in a nonlinear fashion.

\section{Abbreviations}

Mn: Manganese; GAM: Generalised additive model.

\section{Competing interests}

The authors declare that they have no competing interests.

\section{Authors' contributions}

JHE analysed the data and prepared the manuscript. HKC designed the study, supervised data analysis and preparation of the manuscript. $\mathrm{EHH}$ designed the study and managed the MOCEH project. Supervised the birth outcome data and approved the manuscript. MH conducted and managed the data from Cheonan Center of MOCEH. Supervised the data analysis and approved the manuscript. YK conducted and managed the data from Ulsan Center of MOCEH. Supervised the data analysis and approved the manuscript. YCH conducted the quality control of the blood sample analysis, supervised the data analysis, and approved the manuscript. HSP conducted and managed the data from Seoul Center of MOCEH. Supervised the data analysis and approved the manuscript. NSC conducted and approved the nutritional data and supervised the data analysis. All authors read and approved the final manuscript.

\section{Acknowledgments}

This work was financed by Mothers and Children's Environmental Health Study (MOCEH), the Ministry of Environment, Republic of Korea, 2009 and by the Samsung Biomedical Institute grant \#SBRI B-A9-205-2.

\section{Author details}

${ }^{1}$ Department of Social and Preventive Medicine, Sungkyunkwan University School of Medicine, 2066 Seobu-ro, Jangan-gu, Suwon, Gyeonggi-do 440-746, Republic of Korea. ${ }^{2}$ Department of Social and Preventive Medicine, Samsung Biomedical Research Institute, Sungkyunkwan University School of Medicine, 81 Irwon-ro,
Gangnam-gu, Seoul 135-990, Republic of Korea. ${ }^{3}$ Department of Preventive Medicine, Ewha Womans University School of Medicine, 1071 Anyangcheon-ro, Yangcheon-gu, Seoul 158-710, Republic of Korea. ${ }^{4}$ Department of Preventive Medicine, Dankook University College of Medicine, 119 Dandae-ro, Dongnam-gu Cheonan, Chungnam 330-714, Republic of Korea. ${ }^{5}$ Department of Occupational and Environmental Medicine, University of Ulsan College of Medicine, 877 Bangeojinsunhwando-ro, Dong-gu, Ulsan 682-714, Republic of Korea. ${ }^{6}$ Department of Preventive Medicine, Seoul National University College of Medicine, 103 Daehak-ro, Jongno-gu, Seoul 110-799, Republic of Korea. ${ }^{7}$ Department of Nutritional Science and Food Management, Ewha Womans University, 52 Ewhayeodae-gil, Seodaemun-gu, Seoul 120-750, Republic of Korea.

Received: 19 September 2013 Accepted: 16 April 2014 Published: 29 April 2014

\section{References}

1. Aschner $\mathrm{J}$, , Aschner M: Nutritional aspects of manganese homeostasis. Mol Aspects Med 2005, 26:353-362.

2. ATSDR: Toxicological Profile for Manganese. Atlanta, GA: Agency for Toxic Substances and Disease Registry; 2008.

3. Keen $\mathrm{CL}$, Ensunsa JL, Watson MH, Baly DL, Donovan SM, Monaco MH, Clegg MS: Nutritional aspects of manganese from experimental studies. Neurotoxicology 1999, 20:213-223.

4. Aschner M: Manganese: brain transport and emerging research needs Environ Health Perspect 2000, 108(Suppl 3):429-432.

5. Papavasilious PS, Kutt H, Miller ST, Rosal V, Wang YY, Aronson RB: Seizure disorders and trace metals: manganese tissue levels in treated epileptics. Neurology 1979, 29:1466-1473.

6. Hardy G: Manganese in parenteral nutrition: who, when, and why should we supplement? Gastroenterology 2009, 137(5 Suppl):S29-S35.

7. Spencer A: Whole blood manganese levels in pregnancy and the neonate. Nutrition 1999, 15:731-734.

8. Aschner M, Erikson KM, Dorman DC: Manganese dosimetry: species differences and implications for neurotoxicity. Crit Rev Toxicol 2005, 35:1-32.

9. Dörner K, Dziadzka S, Höhn A, Sievers E, Oldigs HD, Schulz-Lell G, Schaub J: Longitudinal manganese and copper balances in young infants and preterm infants fed on breast-milk and adapted cow's milk formulas. Br J Nutr 1989, 61:559-572.

10. Miller ST, Cotzias GC, Evert HA: Control of tissue manganese: initial absence and sudden emergence of excretion in the neonatal mouse. Am J Physiol 1975, 229:1080-1084

11. Hatano S, Nishi Y, Usui T: Erythrocyte manganese concentration in healthy Japanese children, adults, and the elderly, and in cord blood. Am J Clin Nutr 1983, 37:457-460.

12. Colomina MT, Domingo JL, Llobet JM, Corbella J: Effect of day of exposure on the developmental toxicity of manganese in mice. Vet Hum Toxicol 1996, 38:7-9.

13. Sanchez DJ, Domingo JL, Llobet JM, Keen CL: Maternal and developmental toxicity of manganese in the mouse. Toxicol Lett 1993, 69:45-52.

14. Vigeh M, Yokoyama K, Ramezanzadeh F, Dahaghin M, Fakhriazad E, Seyedaghamiri Z, Araki S: Blood manganese concentrations and intrauterine growth restriction. Reprod Toxicol 2008, 25:219-223.

15. Zota AR, Ettinger AS, Bouchard M, Amarasiriwardena CJ, Schwartz J, Hu H, Wright RO: Maternal blood manganese levels and infant birth weight. Epidemiology 2009, 20:367-373.

16. Wood RJ: Manganese and birth outcome. Nutr Rev 2009, 67:416-420.

17. MOCEH Study Group, Kim BM, Ha M, Park HS, Lee BE, Kim YJ, Hong YC, Kim Y, Chang N, Roh YM, Kim BN, Oh SY, Ha EH: The Mothers and Children's Environmental Health (MOCEH) study. Eur J Epidemiol 2009, 24:573-583.

18. Lee $\mathrm{SL}$, Chang YK: A survey on blood pressure and hematic parameters during pregnancy by women of premature delivery. Korean J Community Nutr 2008, 13:903-911.

19. Bae HS: Risk factors affecting the health of pregnant women and fetus. Korean J Community Nutr 2008, 13:805-817.

20. Chen L, Ding G, Gao Y, Wang P, Shi R, Huang H, Tian Y: Manganese concentrations in maternal-infant blood and birth weight. Environ Sci Pollut Res Int 2014, 21:6170-6179.

21. Guan H, Wang M, Li X, Piao F, Li Q, Xu L, Kitamura F, Yokoyama K: Manganese concentrations in maternal and umbilical cord blood: related to birth size and environmental factors. Eur J Public Health 2014, 24:150-157. 
22. Takser L, Lafond J, Bouchard M, St-Amour G, Mergler D: Manganese levels during pregnancy and at birth: relation to environmental factors and smoking in a Southwest Quebec population. Environ Res 2004, 95:119-125.

23. Yu X, Cao L, Yu X: Elevated cord serum manganese level is associated with a neonatal high ponderal index. Environ Res 2013, 121:79-83.

24. Kilburn CJ: Manganese, malformations and motor disorders: findings in a manganese-exposed population. Neurotoxicology 1987, 8:421-429.

25. Bentley OG, Phillips PH: The effect of a manganese deficiency in the chick on the uptake of inorganic phosphate by liver homogenates in vitro. Arch Biochem Biophys 1951, 32:338-346.

26. Rojas MA, Dyer IA, Cassatt WA: Manganese deficiency in the bovine. J Anim Sci 1965, 24:664-667.

27. Hansen SL, Spears JW, Lloyd KE, Whisnant CS: Feeding a low manganese diet to heifers during gestation impairs fetal growth and development. J Dairy Sci 2006, 89:4305-4311.

28. Keen CL, Lonnerdal B, Ensunsa JL, Zidenberg-Cherr S: Manganese. In Guide to Nutritional Supplements. Edited by Caballero B. Oxford, UK: Elsevier Ltd; 2009.

29. Tholin K, Sandström B, Palm R, Hallmans G: Changes in blood manganese levels during pregnancy in iron supplemented and non supplemented women. J Trace Elem Med Biol 1995, 9:13-17.

30. Grace ND: Effect of high dietary Mn levels on the growth rate and the level of mineral elements in the plasma and soft tissues of sheep. N Z J Agricultural Res 1973, 16:177-180.

doi:10.1186/1476-069X-13-31

Cite this article as: Eum et al:: Maternal blood manganese level and birth weight: a MOCEH birth cohort study. Environmental Health 2014 13:31.

\section{Submit your next manuscript to BioMed Central and take full advantage of:}

- Convenient online submission

- Thorough peer review

- No space constraints or color figure charges

- Immediate publication on acceptance

- Inclusion in PubMed, CAS, Scopus and Google Scholar

- Research which is freely available for redistribution 